\title{
Neuronal-Derived Nitric Oxide and Somatodendritically Released Vasopressin Regulate Neurovascular Coupling in the Rat Hypothalamic Supraoptic Nucleus
}

\author{
Wenting Du, Javier E. Stern, and Jessica A. Filosa \\ Department of Physiology, Georgia Regents University, Augusta, Georgia 30912
}

The classical model of neurovascular coupling (NVC) implies that activity-dependent axonal glutamate release at synapses evokes the production and release of vasoactive signals from both neurons and astrocytes, which dilate arterioles, increasing in turn cerebral blood flow (CBF) to areas with increased metabolic needs. However, whether this model is applicable to brain areas that also use less conventional neurotransmitters, such as neuropeptides, is currently unknown. To this end, we studied NVC in the rat hypothalamic magnocellular neurosecretory system (MNS) of the supraoptic nucleus (SON), in which dendritic release of neuropeptides, including vasopressin (VP), constitutes a key signaling modality influencing neuronal and network activity. Using a multidisciplinary approach, we investigated vasopressin-mediated vascular responses in SON arterioles of hypothalamic brain slices of Wistar or VP-eGFP Wistar rats. Bathapplied VP significantly constricted SON arterioles $(\Delta-41 \pm 7 \%)$ via activation of the V1a receptor subtype. Vasoconstrictions were also observed in response to single VP neuronal stimulation $(\Delta-18 \pm 2 \%$ ), an effect prevented by V1a receptor blockade (V2255), supporting local dendritic VP release as the key signal mediating activity-dependent vasoconstrictions. Conversely, osmotically driven magnocellular neurosecretory neuronal population activity leads to a predominant nitric oxide-mediated vasodilation $(\Delta 19 \pm 2 \%)$. Activitydependent vasodilations were followed by a VP-mediated vasoconstriction, which acted to limit the magnitude of the vasodilation and served to reset vascular tone following activity-dependent vasodilation. Together, our results unveiled a unique and complex form of NVC in the MNS, supporting a competitive balance between nitric oxide and activity-dependent dendritic released VP, in the generation of proper NVC responses.

Key words: arteriole; dendrite; hypothalamus; neurovascular; nitric oxide; vasopressin

\section{Introduction}

Neurovascular coupling (NVC) is a critical process that ensures efficient oxygen and nutrient delivery to areas of increased metabolic demands (Attwell et al., 2010). The classical and widely accepted model of NVC implies that activity-dependent axonal glutamate release at synapses evokes the production and release of vasoactive signals from both neurons and astrocytes, which dilate arterioles, increasing in turn cerebral blood flow (CBF). NVC coupling has been largely explored in the cortex (Zonta et al., 2003; Filosa et al., 2004) and hippocampus (Lovick et al., 1999), regions in which neuronal and network activity is largely driven by fast-acting afferent glutamate excitatory inputs. In the hypothalamic magnocellular neurosecretory system (MNS), in

\footnotetext{
Received Sept. 3, 2014; revised Jan. 21, 2015; accepted Feb. 23, 2015.

Author contributions: J.E.S. and J.A.F. designed research; W.D. and J.A.F. performed research; W.D., J.E.S., and J.A.F. analyzed data; W.D., J.E.S., and J.A.F. wrote the paper.

This work was supported by the National Institutes of Health National Heart, Lung and Blood Institute Grant R01 HL089067-02 to J.A.F. and Grant R01HL112225 to J.E.S. We thank Dr. Yiqiang Zhou for technical assistance on arteriole cannulations, Dr. Ki Jung Kim for assistance with $\mathrm{Ca}^{2+}$ imaging recordings, and Maria S. Pitra for assisting with the GFP animal colony.

The authors declare no competing financial interests.

Correspondence should be addressed to Dr. Jessica A. Filosa, Department of Physiology, Georgia Regents University, 1120 15th Street, CA 2092, Augusta, GA 30912. E-mail: jfilosa@gru.edu.

DOI:10.1523/JNEUROSCI.3674-14.2015

Copyright $\odot 2015$ the authors $\quad 0270-6474 / 15 / 355330-12 \$ 15.00 / 0$
}

the supraoptic (SON) and paraventricular (PVN) nuclei, however, concomitantly with glutamatergic stimulation, slow-acting and far-diffusing neuropeptides constitute critical signals regulating neuronal/network activity. Thus, whether the same NVC signaling modality applies to these distinct hypothalamic nuclei is unknown. In addition to the release of vasopressin (VP) and oxytocin (OT) from axonal terminals in the posterior pituitary (Armstrong, 1995), magnocellular neurosecretory neurons (MNNs) release these peptides from their somata and dendrites in an activity-dependent manner (Brown and Bourque, 2004; Ludwig and Leng, 2006; Son et al., 2013). Dendritic peptide release influences the degree/efficacy of afferent inputs (Kombian et al., 1997), individual neuronal firing (Gouzènes et al., 1998), and overall population (Ludwig and Leng, 1997) and interpopulation activity (Son et al., 2013). Whether dendritic release of peptides constitutes an efficient feedback signaling modality regulating local CBF and NVC is unknown.

Nitric oxide (NO) stands as an important vasodilator signal in various brain regions, including cerebellum (Rancillac et al., 2006), hippocampus (Lourenço et al., 2014), and cortex (Cauli et al., 2004; Kitaura et al., 2007). Mainly derived from neuronal NO synthase (nNOS), NO is abundantly produced in the SON (Arévalo et al., 1992; Calka and Block, 1993; Nylén et al., 2001; Stern and Zhang, 2005) and its availability enhanced in response 
to hyperosmotic stimulation (Kadowaki et al., 1994). However, whether NO contributes to NVC-mediated vascular responses in the SON is not known. We propose the MNS as an ideal model to address the general question of whether distinct neuronal phenotypes, signaling modalities, and particular microenvironments surrounding cerebral microvessels are important determinants in NVC, specifically, whether dendritic release of neuropeptides serves as an efficient signaling modality regulating NVC.

Using a multidisciplinary approach in brain slices from the transgenic eGFP-VP rat (Ueta et al., 2005), we assessed activitydependent intraparenchymal SON vascular responses following single VP/OT neuronal activation or osmotically driven population activation. We found that differently from conventional NVC responses, single VP neuronal stimulation evoked SON parenchymal arteriole vasoconstriction, a response mediated by dendritic release of VP. Conversely, osmotically driven MNN population responses led to a predominant NO-mediated vasodilation, in which a delayed VP dendritic release served to reset vascular tone following activity-dependent vascular response. Together, our results unveiled a multifaceted form of NVC in the MNS, supporting a competitive balance between NO and dendritic released VP in the generation of proper NVC responses.

\section{Materials and Methods}

Experimental setup. Experiments were conducted using the Camware high-performance Sensicam attached to a Zeiss microscope (Carl Zeiss) and equipped with a mercury arc lamp (AttoArc 2 HBO $100 \mathrm{~W}$ ). The microscope chamber was continuously perfused with artificial CSF (aCSF) using a peristaltic pump (Miniplus 3, Gilson) at a rate of 2-3 $\mathrm{ml} / \mathrm{min}$. Chamber temperature was maintained at $33^{\circ} \mathrm{C}$ by a single line solution heater (SH-28B, Warner Instruments) connected to a DC power supply (1735A, BK Precision). Patch pipettes were pulled (P-97 puller, Sutter Instruments) to resistances between 4 and $6 \mathrm{~m} \Omega$. Whole-cell patch-clamp recordings were obtained using an Axopatch 200B amplifier (Axon Instruments) and digidata 1440A (Axon Instruments).

Slice preparation. All animal procedures were approved by the Animal Care and Use Committee of Georgia Regents University. Rats were housed in a room maintained at $20^{\circ} \mathrm{C}-22^{\circ} \mathrm{C}$ with a $12 \mathrm{~h}: 12 \mathrm{~h}$ light-dark cycle and given ad libitum access to food and water. Coronal hypothalamic brain slices were prepared from juvenile (P21-P45) 85 female Wistar VP-eGFP rats, 2 male Wistar VP-eGFP rats, or 18 male Wistar rats used for experiments. Following anesthesia with sodium pentobarbital, the brain was removed and cut into 250 - to $300-\mu \mathrm{m}$-thick coronal slices using a vibratome (Leica VT 1200S, Leica Microsystems) in aCSF consisting of (in $\mathrm{mM}$ ) the following: $3 \mathrm{KCl}, 120 \mathrm{NaCl}, 1 \mathrm{MgCl}_{2}, 26 \mathrm{NaHCO}_{3}$, $1.25 \mathrm{NaH}_{2} \mathrm{PO}_{4}, 2 \mathrm{CaCl}_{2}, 10$ glucose, and $0.4 \mathrm{~L}$-ascorbic acid, equilibrated with $95 \% \mathrm{O}_{2}-5 \% \mathrm{CO}_{2}, \mathrm{pH} 7.4$. Brain slices were kept at room temperature until needed.

Video microscopy. Video microscopy was performed to measure changes in arteriole diameter using differential interference contrast (DIC). Parenchymal arterioles were visualized using a $40 \times$ waterimmersion objective. Images were acquired at a rate of 1 frame per second and stored on a computer hard drive for later analysis. U46619 (150 nм) was bath-applied to preconstrict arterioles and induce steady-state vascular tone; U46619 was not used in combination with NO blockade (L-NAME and CPTIO or 7-nitroindazole [7-NI]) as it significantly constricted SON arterioles. High (7.8) or low (6.8) pH aCSF was used to test the viability of the vessel by their vasoconstrictive or vasodilatory response, respectively. For hyperosmotic stimulation experiments, $\mathrm{NaCl}$ was increased to obtain an osmolarity of $340 \mathrm{mOsm}$. For 6.8 and $7.8 \mathrm{pH}$ solutions, the $\mathrm{NaHCO}_{3}$ concentration was either decreased or increased, respectively, and equal amounts of $\mathrm{NaCl}$ substituted to maintain the aCSF osmolarity $\sim 295 \mathrm{mOsm}$.

Electrophysiology. To selectively record from VP neurons, brain slices from VP-eGFP transgenic rats, where eGFP expression is driven by the VP promoter, were used. Likewise, OT neurons were selected based on their lack of eGFP expression in brain slices from VP-eGFP transgenic rats. The VP-eGFP neuron, or non-eGFP (OT) neuron near the preconstricted vessel, was detected using fluorescence microscopy and patched using DIC and recordings performed using the whole-cell configuration. The internal solution consisted of (in mM) the following: $135 \mathrm{~K}^{+}$gluconate, 10 HEPES, 0.2 EGTA, $10 \mathrm{KCl}, 0.9 \mathrm{MgCl}_{2}, 4 \mathrm{Mg}_{2} \mathrm{ATP}, 0.3$ $\mathrm{Na}_{2} \mathrm{GTP}$, and 20-phosphocreatine, $\mathrm{pH}$ to 7.25 adjusted with $\mathrm{KOH}$. In current-clamp mode, positive current was injected to induce action potentials to a frequency range between 3 and $10 \mathrm{~Hz}$ for $2-2.5 \mathrm{~min}$. In spontaneously discharging neurons, minimal hyperpolarizing current was injected to eliminate firing activity.

Parenchymal arteriole cannulation. Details of the cannulation technique were described previously (Kim and Filosa, 2012). Briefly, cannulas (ID $1.17 \mathrm{~mm}$ and OD $1.50 \mathrm{~mm}, \mathrm{G} 150 \mathrm{TF}-3$, Warner Instruments) were pulled with a micropipette puller (P-97 puller Sutter Instruments) and filled with internal cannula solution consisting of (in $\mathrm{mm}$ ) the following: $3 \mathrm{KCl}, 135 \mathrm{NaCl}, 1 \mathrm{MgCl}_{2}, 10$ glucose, $10 \mathrm{HEPES}$, and $2 \mathrm{CaCl}_{2}$, plus $1 \%$ albumin with osmolarity at $300-305$ mosmol $1^{-1}$ and $\mathrm{pH} 7.4$ adjusted with $\mathrm{NaOH}$. To continuously monitor the pressure of the perfusion system, the cannula was connected to a pressure transducer (PS/ 200, Living System Instrumentation); luminal flow rate was controlled with a syringe pump (11 PLUS, Harvard Apparatus). At the end of each experiment, $100 \mu \mathrm{M}$ papavarine was added to aCSF containing zero $\mathrm{Ca}^{2+}$ to maximally dilate the arteriole.

Vascular smooth muscle cell calcium imaging. SON slices were incubated with the calcium indicator Fluo-4AM (Invitrogen, F-14201, 40 $\mu \mathrm{M}$ ) and $2.5 \mu \mathrm{l} 20 \%$ pluronic acid (Invitrogen, P3000MP) in a $95 \%$ $\mathrm{O}_{2} / 5 \% \mathrm{CO}_{2}$ oxygenated chamber for $100 \mathrm{~min}$, after which slices were moved to equilibrated aCSF chambers and maintained at room temperature for a short period until imaging. Images were acquired at a rate of 4 image/s using a $60 \times$ objective (Nikon). Calcium imaging was analyzed as previously described (Filosa et al., 2004) using SparkAN software (Dr. Adrian Bonev, University of Vermont, Burlington, VT). Fluorescence intensity was determined within $20 \times 20$ pixel squares placed over vascular smooth muscle cell (VSMC) with baseline fluorescence (F0) determined from 20 image frames showing no activity. Fractional fluorescence (F/F0) was calculated, and peaks were automatically detected from oscillations crossing a set threshold value $(>0.15 \mathrm{~F} / \mathrm{F} 0)$ and summarized as $\mathrm{Ca}^{2+}$ oscillations peak frequency $(\mathrm{Hz})$.

Immunofluorescence. Immunofluorescence was used to show the relationship between VP neurons and arterioles. VP neurons were stained by adding Alexa-555 (100 $\mu \mathrm{M})$ to the internal recording solution. At the end of the experiment, the SON slice was incubated for 15-30 min in aCSF containing Alexa-633 (2 $\mu \mathrm{M}$ ), shown to stain arterioles (Shen et al., 2012). Slices were then fixed in $4 \%$ PFA PBS (4\% PFD) for $72 \mathrm{~h}$ at $4^{\circ} \mathrm{C}$. Following fixation, sections were incubated in $0.5 \%$ Triton X-100, $0.04 \%$ $\mathrm{NaN}_{3}$, and $10 \%$ normal horse serum for $1 \mathrm{~h}$. For immunofluorescence reactions, sections were incubated overnight in polyclonal guinea pig anti-(Arg8)-VP (1:200,000, Bachem). Reactions with primary antibodies were followed by a $4 \mathrm{~h}$ incubation with secondary antibodies (donkey anti-guinea pig-Cy3 labeled, 1:250 dilution, in PBS containing 0.5\% Triton X-100 and $0.04 \% \mathrm{NaN}_{3}$, Jackson ImmunoResearch Laboratories). Mounted slices were imaged using a LSM510 confocal microscope (Zeiss Microimaging).

Drugs. The thromboxane $\mathrm{A}_{2}$ receptor agonist 9,11-dideoxy-11 $\alpha, 9 \alpha$ epoxymethanoprostaglandin $\mathrm{F}_{2 \alpha}$ (U-46619) (Cayman Chemical) was prepared as a stock in DMSO and subsequently added to the aCSF. DMSO content in the experimental solutions was $<0.1 \%$. Alexa- 555 and Alexa-633 were obtained from Invitrogen. All other chemicals were purchased from Sigma.

Data analysis. Arteriolar diameter data (IR-DIC) was analyzed using SparkAN (created by Dr. Adrian D. Bonev, University of Vermont, Burlington, VT). Changes in internal diameter throughout the experiment were determined from the distance between two set point values across the arteriole. Initial diameter was determined during the first $\sim 2$ min of sampling, during which time arterioles lack vascular tone. Steady-state vascular tone is expressed as the percentage diameter value from the initial diameter before U46619 preconstricted arterioles. Vascular tone defined as diameter (\%) and the magnitude of the vascular response ( $\Delta$ diameter $\%$ ) were calculated as previously described (Blanco et al., 
2008). Namely, diameter $(\%)=100 \% \times($ initial diameter - steady-state diameter induced by U46619)/initial diameter and $\Delta$ diameter $(\%)=100 \% \times($ averaged peak diameter during response - steady-state diameter)/steadystate diameter. Neuronal firing activity was analyzed using either Clampfit 10.2 or Mini Analysis Program version 6.0.3 (Synaptosoft). Summary data are expressed as mean \pm SEM. Differences between two means from the same arteriole were tested using paired Student's $t$ test. Differences between two means from different arterioles were tested using unpaired Student's $t$ test. Differences above two means from the same arteriole or neuron were determined using two-tailed or repeated-measures one-way ANOVA followed by Bonferroni post-test, as indicated. Data comparison shown in Figure $9 A$ was done using repeated measures two-way ANOVA followed by Bonferroni post-test. A $95 \%(p<0.05)$ confidence interval was used to test statistical significance.

\section{Results}

\section{VP constricts SON arterioles via V1a} receptor activation

As a first step to determine the effect of VP on SON parenchymal arterioles, their response to bath-applied VP was monitored. To compensate for the lack of myogenic (pressure-induced) tone, as arterioles in brain slices are not perfused and pressurized (Filosa et al., 2004), SON arterioles were first preconstricted with the thromboxane agonist U46619 (150 $\mathrm{nM})$ to a steady-state vascular tone of $-29 \pm 4 \%(n=6)$, comparable to that previously reported (Blanco et al., 2008) (Fig. $1 A-D$ ). In the presence of U46619, bath-applied VP $(1 \mu \mathrm{M})$ transiently and reversibly constricted $\mathrm{SON}$ arterioles by $\Delta-41 \pm 7 \%(n=6)$ from steady-state tone (Fig. 1C,D). Onset vasoconstriction occurred $0.5 \pm 0.1 \mathrm{~min}$ from the time VP reached the tissue. As a positive control, at the end of some experiments, the reactivity of the arteriole was assessed by measuring its response to high $\mathrm{pH}$ aCSF, $\mathrm{pH}$ 7.8. As previously reported in cerebral arterioles (Apkon and Boron, 1995) and indicative of a healthy arteriole, alkalinization induced marked vasoconstrictions $(\Delta-50 \pm 9 \%, n=4$; Fig. $1 C, D)$ with an onset of $0.6 \pm 0.3 \mathrm{~min}$ from the time the high $\mathrm{pH}$ aCSF reached the tissue. VP-mediated vasoconstrictions were blocked by the selective V1a receptor antagonist, V2255 ( $1 \mu \mathrm{M}$; Figure $1 E, F)$. V2255, however, did not affect per se baseline vascular tone. On the other hand, high $\mathrm{pH}$ still induced a significant vasoconstriction of the same arteriole $(\Delta-47 \pm 11 \%, n=5$; Figure $1 E, F)$. Finally, to further verify the VP effect on SON arterioles, we measured VSMC $\mathrm{Ca}^{2+}$ changes in response to bath-applied VP $(1 \mu \mathrm{M})$. As shown in Figure $1 G, H$, VP significantly increased VSMC $\mathrm{Ca}^{2+}$ oscillation frequency $(0.055 \pm$ $0.024 \mathrm{~Hz}$ to $0.148 \pm 0.013 \mathrm{~Hz}$ ). Together, these data support the ability of VP to increase $\mathrm{Ca}^{2+}$ in VSMC and constrict SON intraparenchymal arterioles via $\mathrm{V} 1$ a receptor activation.
B
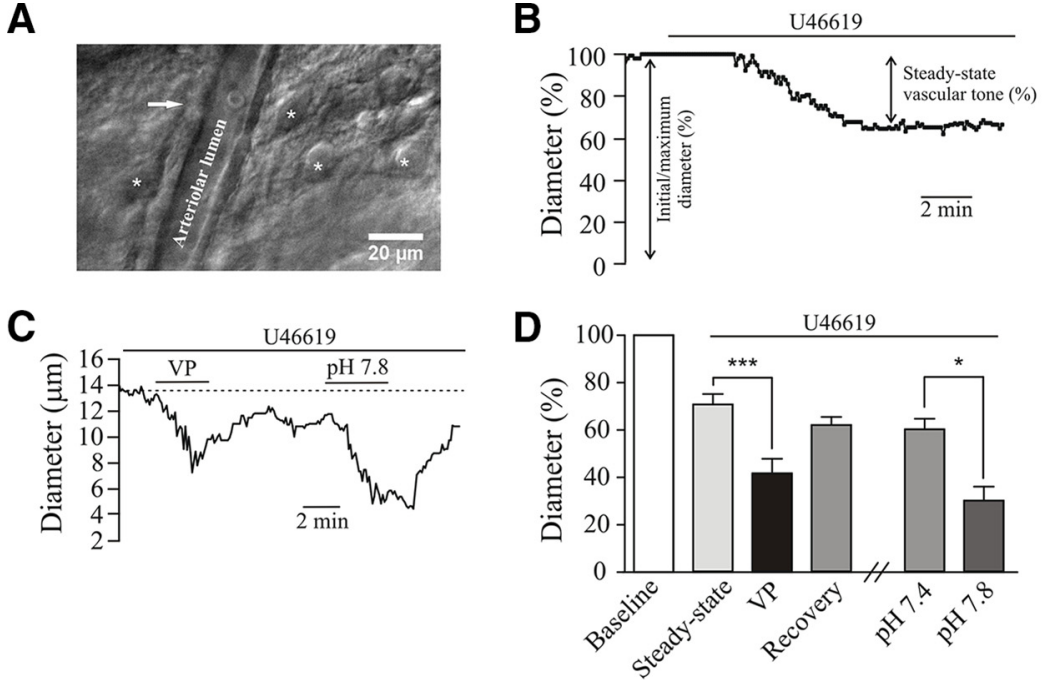

F
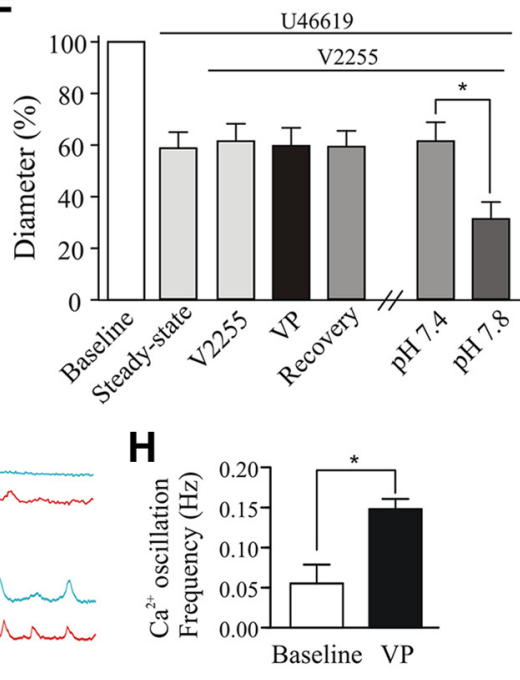

Figure 1. VP induced SON parenchymal arteriole constriction via V1a receptor activation. $\boldsymbol{A}$, Representative DIC image of a (1)

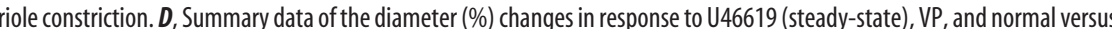
.8. and high pH + V2255 (7.8). G. Representative image (left) and traces (right) for VSMC C ${ }^{2+}$ activity in response to bath-applied VP. $\boldsymbol{H}$, Summary data of VSMC $\mathrm{Ca}^{2+}$ oscillation frequency in the SON. Data are mean \pm SEM. Values were compared using repeated-measures one-way ANOVA followed by Bonferroni post-test; paired $t$ test was used for $\mathrm{pH}$ data as well as frequency data comparison. ${ }^{*} p<0.05{ }^{* * *} p<0.001$.

\section{Single vasopressinergic neuronal activation preferentially} constricts SON arterioles

Two main peptidergic neuronal population subtypes reside in the SON (i.e., VP and OT neurons). Thus, we determined whether the selective activation of a single VP neuron was sufficient to evoke SON arteriole responses. Using the VP-eGFP transgenic rat (Ueta et al., 2005), we obtained whole-cell patch-clamp recordings from identified VP neurons. Recorded neurons had a mean resting membrane potential of $-59.46 \pm 1.02 \mathrm{mV}$, input resistance $491.1 \pm 27.19 \mathrm{M} \Omega$, and capacitance of $22.60 \pm 1.26 \mathrm{pF}(n=$ $44)$. For further characterization of the recorded neuron, Alexa$555(100 \mu \mathrm{M})$ was added to the internal recording solution (Figure $2 A$ ). To examine the effect of single VP neuronal activation on arteriolar diameter changes, a burst of action potentials (2-2.5 min duration) was evoked in the patched neuron, whereas simul- 
A

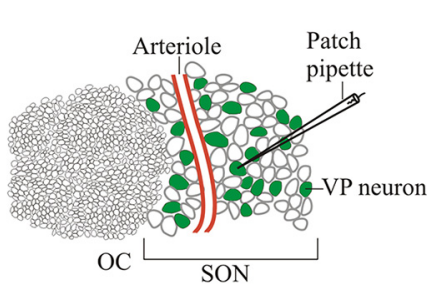

B

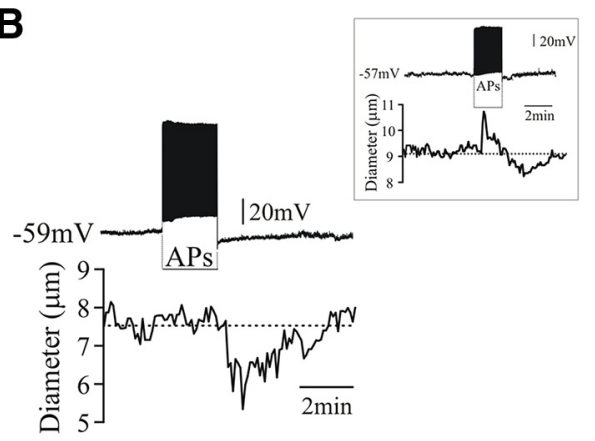

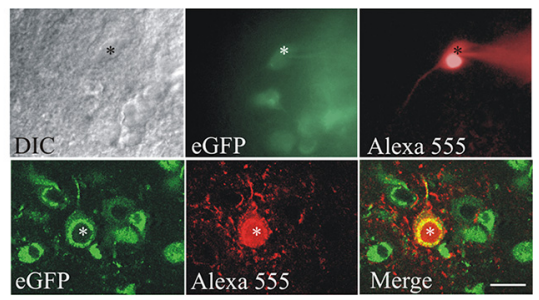

C

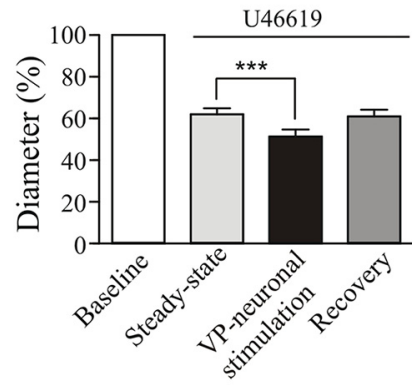

E

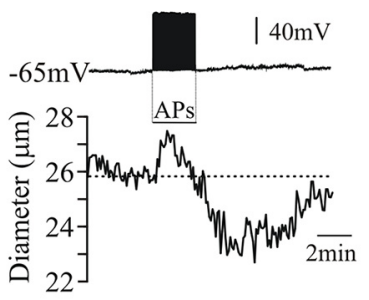

Figure 2. Single VP neuronal stimulation preferentially constricts SON arterioles. $\boldsymbol{A}$, Left, schematic diagram of an SON brain slice showing the relative position of the stimulated neuron and recording pipette to the monitored arteriole. Top row, DIC image (left) of a GFP-positive VP neuron (eGFP) (green, middle) also loaded with Alexa-555 (red, far right). Bottom row, Confocal image following slice fixation showing GFP-positive VP neurons (left), the recorded neuron loaded with Alexa-555 (middle), and the merged image (right). $\boldsymbol{B}$, Representative traces showing simultaneous action potential firing in the stimulated VP neuron (top) and diameter changes in the SON arteriole in response to a 2 min depolarizing pulse (arteriole preconstricted with U46619), showing a vasoconstriction response. Inset, Example of a biphasic vascular response to single VP neuronal stimulation. C, Summary data of diameter changes (\%) in response to bath-applied U46619 (steady-state) and single VP-neuronal stimulation. D, Schematic diagram of the cannulated arteriole and patched VP neuron in the SON slice. $\boldsymbol{E}$, Representative simultaneous action potential and diameter traces of the stimulated VP neuron (top) and pressurized and perfused SON arteriole in response to a 2 min depolarization pulse. Data are mean \pm SEM. Repeated-measures one-way ANOVA followed by Bonferroni post-test was used for data comparison. ${ }^{* * *} p<0.001$.

taneous vascular responses were measured in the nearby preconstricted arteriole. Single VP neuronal stimulation primarily evoked arteriole vasoconstriction $(\Delta-18 \pm 3 \%$ from steady-state tone, $n=12$ of 13; Figure $2 B, C)$. Interestingly, in 3 of 13 vessels, a transient vasodilation preceded the vasoconstriction (Fig. $2 B$, inset), whereas in one case, the arteriole responded only with a vasodilatation. Overall, vasodilatory responses were characterized by a $\Delta 15 \pm 5 \%(n=4)$ increase in diameter, preceding significantly the evoked vasoconstrictions $(0.4 \pm 0.2 \mathrm{~min}, n=4$ vs $2.9 \pm$ $0.6 \min , n=12, p=0.029$ ).

Although the use of U46619 to preconstrict arterioles to near physiological levels has been widely used (Filosa et al., 2006; Metea and Newman, 2006; Blanco et al., 2008), under these condition, arterioles lack luminal pressure and flow and, thus, do not develop myogenic tone. Thus, to validate vascular responses under more physiological conditions, experiments were repeated in perfused/pressurized SON arterioles, a technique we recently implemented for the first time to the slice preparation (Kim and Filosa, 2012) (Fig. 2D). Although applying this approach in conjunction with recordings from a nearby neuron is technically challenging, we were able nonetheless to effi-

ciently assess the consistency of our results in a subset of experiments. Following cannulation and pressurization, arterioles exhibited $\Delta-22 \pm 6 \%$ $(n=3)$ myogenic tone determined from the maximum diameter measured in zero $\mathrm{Ca}^{2+}$ and papavarine (see Materials and Methods) (Cipolla et al., 2009). Under these conditions, and similar to what we observed with U46619, single VP neuronal stimulation induced a $\Delta-14 \pm 2 \%$ constriction from myogenic tone $(n=3)$. Consistent with observations in arterioles preconstricted with U46619, in one-third of arterioles, a transient dilation $(\Delta 6 \%)$ preceded the vasoconstriction $(\Delta-11 \%)$ (Fig. $2 E$ ). The onset for the vasodilatory response was $0.1 \mathrm{~min}$, whereas the mean onset for vasoconstrictions was $3.2 \pm 0.4 \mathrm{~min}$ $(n=3)$.

\section{Bath-applied OT and single OT neuronal stimulation fail to induce vascular effects in the SON}

As with VP, OT has been characterized to have vasoactive effects inducing vasoconstriction via $\mathrm{V} 1 \mathrm{aR}$ activation or vasodilation via the production of endothelialderived NO (Maigaard et al., 1986; Suzuki et al., 1992; Oyama et al., 1993; Chen et al., 1999; Loichot et al., 2001). To determine whether in the SON OT evoked a vascular response as that observed with $\mathrm{VP}$, we measured SON arteriole responses to bath-applied OT $(1 \mu \mathrm{M})$. As shown in Figure 3, neither bath-applied OT $(\Delta-2 \pm$ $8 \%, n=5$; Fig. $3 A, B)$ nor single OT neuronal stimulation $(\Delta 1 \pm 5 \%, n=6$; Fig. $3 C, D$ ) evoked a vascular effect on SON arterioles, suggesting that OT is not a key signal in regulating $\mathrm{NVC}$ in the SON.

\section{NO and VP were released in response to single VP neuronal stimulation}

The presence of both activity-dependent vasoconstriction and vasodilation following single VP neuronal stimulation (Fig. $2 B$, inset) is suggestive of the corelease of at least two opposing vasoactive signals from the same activated neuron. VP and NO, potent vasoconstrictor and vasodilatory signals, respectively, are known to be released in an activity-dependent manner within the SON (Dawson et al., 1991; Neumann et al., 1993; Stern and Zhang, 2005; Ludwig and Leng, 2006). Thus, to assess their contribution to the evoked vasoactive responses induced by the activation of a single VP neuron, experiments were repeated in the presence of V1a receptor (V2255) blockade and NOS inhibitors. As it was observed with bath-applied VP, the presence of V2255 abrogated vasoconstrictor responses evoked by single VP neuronal stimulation, notably unmasking, in 7 of 10 arterioles, activitydependent vasodilations $(\Delta 18 \pm 7 \%$ vasodilation from steady-state tone, $n=10$; Figure $4 A, B)$. All arterioles tested, including those that did not show a VP-mediated vascular response $(n=3)$, constricted to high $\mathrm{pH}$ aCSF $(\Delta-44 \pm 8 \%, n=7)$. For the 7 of 10 
arterioles that showed a dilatory response in the presence of V2255, the onset occurred at $0.3 \pm 0.2 \min (n=7)$ from the start of the depolarizing stimulus. Activity-dependent evoked vasodilatory responses in the presence of the $\mathrm{VlaR}$ blocker were blocked by the combined used of an NO synthase blocker L-NAME $(100 \mu \mathrm{M})$ and the NO scavenger cPTIO $(100 \mu \mathrm{M})$, resulting thus in the lack of any significant vascular response $(\Delta-3 \pm 6 \%$, $n=7$ ) (Fig. 4C,D). On the other hand, arterioles tested with low $\mathrm{pH}$ (6.8) aCSF still responded with a vasodilation $(\Delta 35 \pm$ $12 \%, n=6$; Figure $4 C, D)$. Together, our data are consistent with the notion that increasing the firing discharge of VP neurons leads to the local corelease of opposing vasoactive signals, with a predominant vasoconstrictor response mediated by somatodendritic release of the neuropeptide VP and a weaker, and thus masked, vasodilatory response mediated by local release of NO.

\section{Vascular responses are independent of basal tone, neuronal firing rate, or the topographical interrelationship between VP neurons and the nearby SON arteriole}

To determine whether the level of basal vascular tone was a critical factor impacting the magnitude and/or polarity of the vascular response (i.e., vasodilation vs vasoconstriction), as we previously showed in the cortex (Blanco et al., 2008), we plotted the percentage change in vascular diameter $(\Delta$ diameter $(\%))$ evoked by single VP neuronal depolarization as a function of basal steady-state vascular tone (Figure $5 A$ ). In contrast to our previous observations in the cortex (Blanco et al., 2008), we failed to observe a significant correlation between these two parameters, both for the predominant vasoconstriction $\left(r^{2}=\right.$ $0.082, n=13)$ and vasodilatory $\left(r^{2}=\right.$ $0.087, n=13$ ) responses observed. Moreover, mean basal steady-state tone was not significantly different between arterioles showing vasoconstriction and vasodilatory responses $(39 \pm 3 \%, n=13$ vs $42 \pm$ $3 \%, n=13$, respectively).

We then determined whether the vascular response was dependent on the degree of evoked neuronal firing activity. A plot of percentage changes in diameter $(\Delta$ diameter $(\%))$ as a function of evoked neuronal firing frequency failed to unveil a correlation between the vascular response (\%) and the evoked neuronal firing frequency in the case of vasoconstrictions $\left(r^{2}=0.0008\right.$, $n=13)$ or vasodilations $\left(r^{2}=0.086\right.$,
A

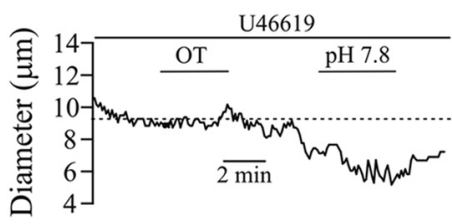

B

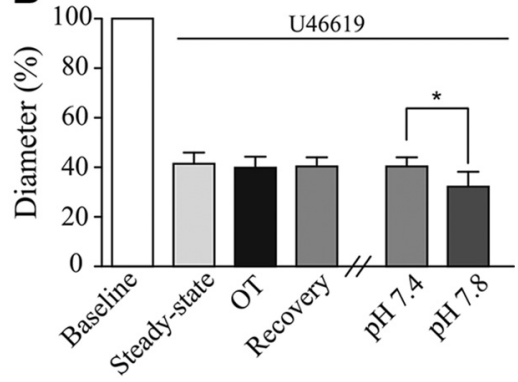

C

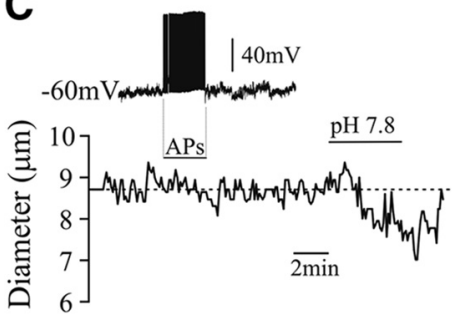

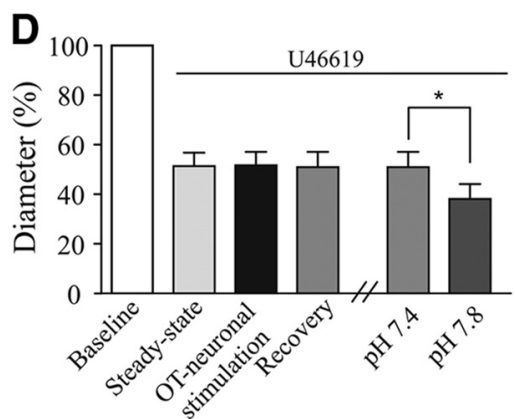

Figure 3. Bath-applied OT and single oxytocinergic neuronal stimulation fail to induce vascular responses in the SON. $\boldsymbol{A}$, Representative diameter trace for bath-applied OT in the SON. B, Summary data of diameter (\%) changes in response to bathapplied OT. C, Representative traces showing simultaneous action potential firing in the stimulated OT neuron (top) and diameter changes in the SON arteriole in response to a 2 min depolarizing pulse (arteriole preconstricted with U46619). $\boldsymbol{D}$, Summary data of diameter changes (\%) in response to single $0 \mathrm{~T}$-neuronal stimulation. Data are mean \pm SEM. Values were compared using repeated-measures one-way ANOVA followed by Bonferroni post-test; paired $t$ test was used for $\mathrm{pH}$ data comparison. ${ }^{*} p<0.05$.

A

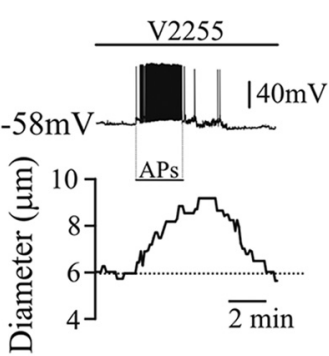

C $\underline{\text { C2255+L-NAME }+\mathrm{CPTIO}}$

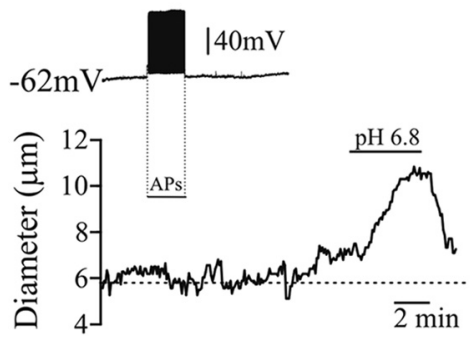

B

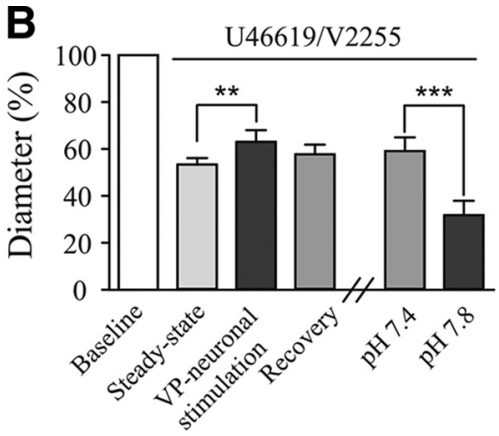

D

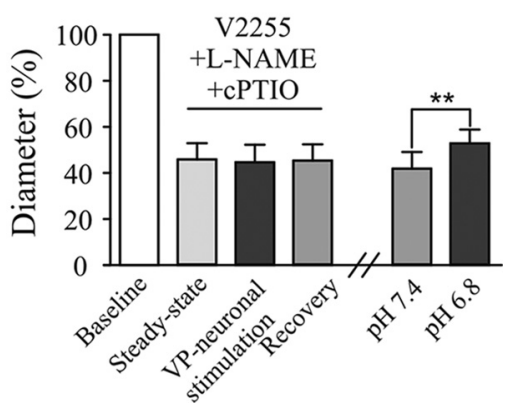

Figure 4. Arteriole responses to single VP neuronal stimulation in the presence of V1aR and/or N0 blockade. $A$, Representative traces showing simultaneous action potential firing in the stimulated VP neuron (top) and diameter changes in the SON arteriole in response to a 2 min depolarizing pulse (arteriole preconstricted with U46619) in the presence of the V1aR blocker V2255. B S Summary data of diameter changes (\%) in response to bath-applied U46619 and single VP-neuronal stimulation in the presence of V2255. C, Representative traces showing simultaneous action potential firing in the stimulated VP neuron (top) and diameter changes in the SON arteriole in response to a 2 min depolarizing pulse (arteriole preconstricted with U46619) in the presence of V2255 and N0 blockade (L-NAME + CPTIO). D, Summary data of diameter changes (\%) in response to single VP-neuronal stimulation in the presence of V2255, L-NAME, and CPTI0. Arteriole viability was assessed by its vasoconstrictive response to high pH (7.8) or low pH (6.8) aCSF. Data are mean \pm SEM. Values were compared using repeated-measures one-way ANOVA followed by Bonferroni post-test; paired t test was used for pH data comparison. ${ }^{* *} p<0.01 .{ }^{* *} p<0.001$. 
A

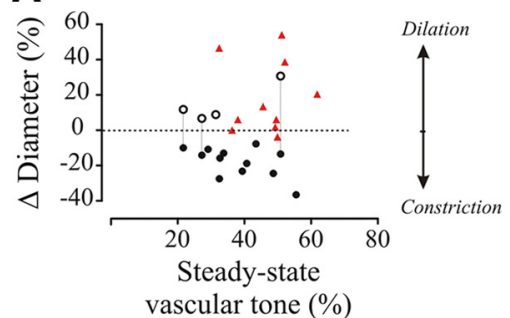

\section{C}

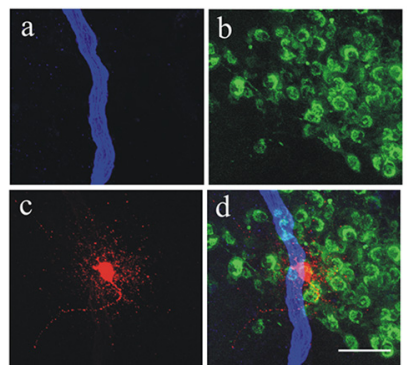

B

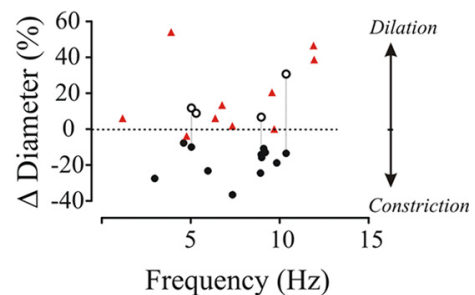

D

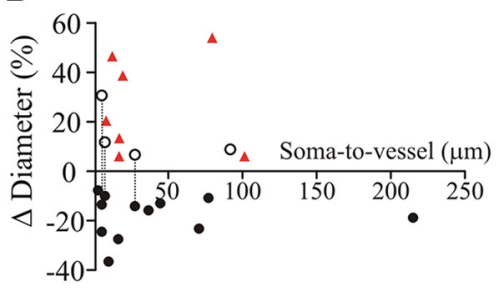

Figure 5. Functional and structural relationship between the recorded VP neuron and the nearby SON arteriole. $A, B$, Plot of changes in vascular diameter in response to single VP neuronal depolarization as a function of basal vascular tone $(\%)(\boldsymbol{A})$ and evoked neuronal firing frequency $(\boldsymbol{B})$ in the presence and absence of the V1aR blocker V2255. C, Representative confocal image of the recorded VP neuron and SON arteriole. Green represents VP neuron in the VP-eGFP transgenic rat. Red represents recorded VP neuron loaded with Alexa-555. Blue represents SON arteriole stained with Alexa-633. Scale bar, $40 \mu \mathrm{m}$. D, Summary data of vascular diameter changes (\%) as a function of the distance between the neuronal soma and the recorded arteriole. Vasoconstrictions (\%) (black closed circles), vasodilations (\%) (black open circles), biphasic vascular responses (vasodilation followed by a vasoconstriction in the same arteriole connected with a with dashed line). Triangles represent vascular diameter changes (\%) in response to single VP neuronal stimulation in the presence of V2255.

A

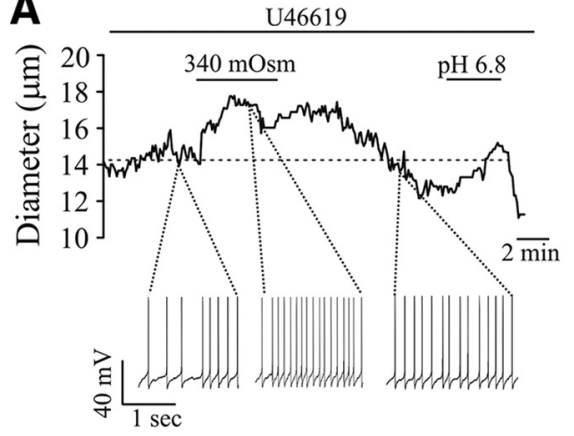

C

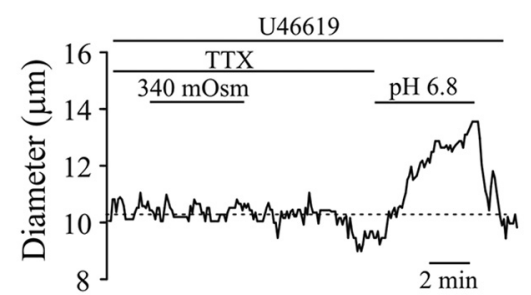

B

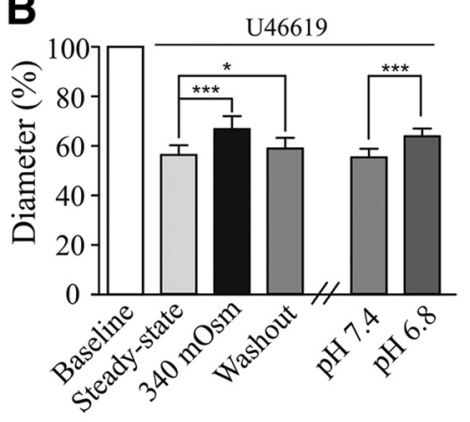

D

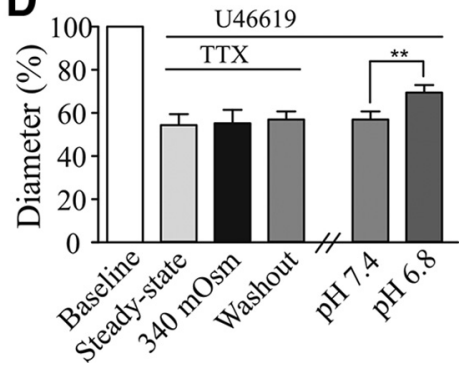

Figure 6. Hyperosmotic stimulation-induced neuronal and vascular responses in the SON. $\boldsymbol{A}$, Representative diameter trace of an osmotically driven vasodilatation. Samples of VP neuronal firing activity during the respective time periods are shown below. $\boldsymbol{B}$, Summary data of diameter (\%) changes in response to hyperosmotic stimulation. C, Representative trace of the effect of hyperosmotic stimulation on vascular diameter (\%) in the presence of TTX.D, Summary data of changes in diameter (\%) in response to hyperosmotic stimulation in the presence of TTX. Arteriole viability was assessed by its vasodilatory response to low pH (6.8) aCSF. Data are mean \pm SEM. Values were compared using repeated-measures one-way ANOVA followed by Bonferroni post-test; paired $t$ test was used for pH data comparison. ${ }^{*} p<0.05 .{ }^{* *} p<0.01$. ${ }^{* * *} p<0.001$.

$n=13$; Figure $5 B$ ). Moreover, the mean degree of evoked neuronal activity was not significantly different between arterioles showing vasoconstriction or vasodilatory responses $(7.4 \pm 0.7 \mathrm{~Hz}, n=13$ vs $7.6 \pm 0.9 \mathrm{~Hz}, n=13)$.
Finally, we examined the topographical interrelationship between the responsive $\mathrm{SON}$ arteriole and the stimulated $\mathrm{VP}$ neuron. The distance from the recorded VP neuronal somata and the SON arteriole was measured under DIC. In a subset of experiments, to better illustrate the interrelationship between the patched neuron and the recorded arteriole, slices were incubated in Alexa-633 $(2 \mu \mathrm{M})$, a specific arteriole wall marker (Shen et al., 2012). Figure $5 C$ shows an example of an Alexa633-stained SON arteriole (shown in blue), VP neurons expressing GFP (shown in green), and the recorded VP neuron labeled with Alexa-555 (shown in red). The mean distance from the somata of the patched neuron to the monitored arteriole was $43.19 \pm 10.26 \mu \mathrm{m}(n=23)$. As shown in Figure $5 D$, the overall mean distance from neuronal somata to the vessel was not significantly different between evoked vasoconstrictions $(40.13 \pm 16.16$ $\mu \mathrm{m}, n=13)$ and vasodilations (39.34 \pm $9.86 \mu \mathrm{m}, n=13)$. Moreover, there was no correlation between the magnitude/polarity of the vascular response and the soma-vessel distance (constriction: $r^{2}=$ 0.003, $n=13$; dilation: $r^{2}=0.044, n=$ 13). Together, these results support the notion that the polarity of the vascular response is not dependent on of the degree of firing activity, basal vascular tone, or neuron-to-vessel distance, but rather, that these opposing responses are mediated by two distinct signaling mechanisms and their relative balance.

\section{An acute osmotic stimulus evokes VP/ $\mathrm{NO}$-mediated vascular responses in the SON}

Our studies indicate that evoked firing activity in VP neurons by direct current injection resulted in a predominantly VPmediated vasoconstrictive response and that, when this was blocked, an NOmediated vasodilatory response was unmasked. To study whether a similar vascular phenomenon was observed during a "population" rather than a unitary neuronal response, we evaluated SON neurovascular responses to a hyperosmotic challenge, one of the classical physiological challenges that increase the activity of the VP neuronal population (Leng, 1980; Bourque, 1989; MacGregor and Leng, 2013). We recorded vascular tone changes in response to an acute hyperosmotic stimulus to the entire slice ( $\Delta 40 \mathrm{mOsm}, 4 \mathrm{~min})$. In a few cases ( 4 of 10$)$, simultaneous VP neuronal firing activity was also recorded. As previously reported (Leng, 1980), VP neuronal firing activity increased in response to the hyperosmotic stimulus (from $5.5 \pm 1.6$ to $11.0 \pm 3.4 \mathrm{~Hz}$, 
$\Delta 107 \pm 60 \%$ from baseline, $n=4)$. In contrast to observations following single VP neuronal stimulation, we found that arterioles dilated by $\Delta 19 \pm 2 \%(n=10)$ from steady-state tone with peak responses occurring $3.8 \pm 0.3 \mathrm{~min}$ from the onset of the stimulus (Figure 6A,B). Although on average, all arterioles recovered their diameter back to baseline values $(n=10$, see washout diameter; Fig. $6 B)$, in 5 of these arterioles and as shown in the representative trace, a rebound constriction $(\Delta-14 \pm 4 \%)$ was observed (Fig. $6 A)$. To confirm that osmotically driven vascular responses were dependent on activity-mediated, neuronally derived signals, the hyperosmotic stimulation was repeated while blocking action potential firing (TTX, $0.5 \mu \mathrm{M}$ ). Under these conditions, hyperosmotic stimulation failed to induce a vascular response $(\Delta 2 \pm 3 \%$ from steady-state tone, $n=7$; Fig. $6 C, D$; see Fig. 9).

To determine whether the osmotically evoked vasodilation involved NO signaling, experiments were repeated in the presence of L-NAME $(100 \mu \mathrm{M})$ and CPTIO $(100 \mu \mathrm{M})$. In this condition, hyperosmotic stimulation still evoked a significant increase in VP neuronal firing activity (from $5.9 \pm 0.8$ to $12.4 \pm 2.3 \mathrm{~Hz}, \Delta 116 \pm 39 \%$, from baseline, $n=5$ ). Likewise, in the presence of NOS blockade, hyperosmotic stimulation continued to induce a smaller, yet significant, vasodilatory response $(\Delta 9 \pm$ $2 \%$ from steady-state tone, $n=8$; Fig. $7 A, B)$. Importantly, the presence of NOS blockers resulted in a pronounced peak rebound constriction $(\Delta-10 \pm 4 \%)$, an effect observed in all vessels studied (Fig. $7 A, B$; see $9 A$ ). Previous studies have demonstrated hyperosmotic stimulation-induced NO release from a neuronal source (Kadowaki et al., 1994; da Silva et al., 2013). Thus, to gain further information on the potential source of NO, experiments were repeated in the presence of the specific nNOS blocker 7-NI. Bath-applied 7-NI alone constricted ( $-46 \pm 5 \%$, $n=8$; Fig. $7 C, D)$ SON arterioles, suggesting the presence of tonically released NO from neurons. Moreover, and consistent with the notion that neuronal NO contributes to hyperosmotic stimulation-induced dilations, the presence of 7-NI blunted the hyperosmotic stimulation-evoked vascular response $(\Delta 11 \pm 5 \%$, $n=8$, Fig. $7 C, D)$. Together, these results support the notion that osmotic stimulation mediates a vasodilation mostly via nNOSderived NO and that a concomitant release of VP evokes a vasoconstriction that is observed as a late rebound, which helps in the reestablishment of steady-state tone following osmotically mediated vasodilations. Rebound constriction was not observed in the presence of 7-NI.

When the osmotic stimulation was performed in the presence of the V1a antagonist V2255 (1 $\mu \mathrm{M})$, pronounced vasodilatory responses were still observed $(\Delta 35 \pm 8 \%, n=7$; Fig. $7 E, F)$, which were significantly larger than those in control conditions $(p<0.05)$. However, the rebound constrictions observed during
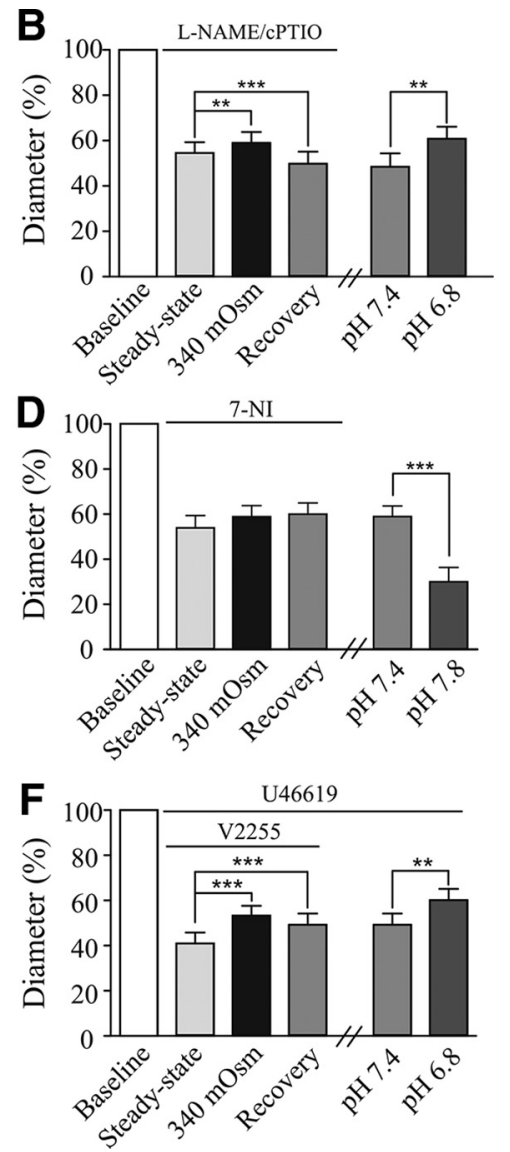

Figure 7. Role of NO and VP in osmotically driven NVC in the SON. A, Representative diameter trace of osmotically induced vasodilation and rebound vasoconstriction in the presence of L-NAME and CPTIO. Samples of VP neuronal activity during the resperiods are shown below. $\boldsymbol{B}$, Summary data of changes in diameter (\%) in response to osmotic stimulation in the

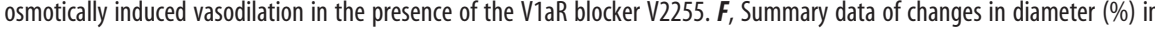
列 pH (6.8) aCSF. Data are mean \pm SEM. Values were compared using repeated-measures one-way ANOVA followed by Bonferroni post-test; paired $t$ test was used for $\mathrm{pH}$ data comparison. ${ }^{* *} p<0.01 .{ }^{* * *} p<0.001$.

the washout period were absent, observing indeed a persistent dilation during this period $(\Delta 23 \pm 8 \%$ from baseline, $n=7$; Fig. $7 E$, F; see Fig. $9 A$ ), which on average did not return to baseline, at least within the recovery time period of our recordings. Consistent with viable arterioles, all vessels dilated to low $\mathrm{pH}$ (6.8) aCSF $(\Delta 24 \pm 6 \%, n=7)$.

\section{VP-mediated vasoconstriction is independent of functional astrocytes}

In the cortex (Takano et al., 2006; Iadecola and Nedergaard, 2007), astrocytes are key intermediaries in NVC-mediated arteriole vasodilation. However, astrocytic stimulation has also been linked to arteriole vasoconstriction (Mulligan and MacVicar, 2004; Metea and Newman, 2006). Because astrocytes express VP receptors (Hatton et al., 1992; Zhao and Brinton, 2003), and VP was recently shown to stimulate astrocyte activity (Haam et al., 2014), we determined their contribution to VP- and hyperosmotic-mediated vascular responses. Experiments were performed in the presence of the gliotoxin DL- $\alpha$-aminoadipic acid (L-AAA), previously shown to impair astrocyte function (Huck et al., 1984). After achieving steady-state vascular tone in response to U46619 (150 nM), slices were also perfused with aCSF containing L-AAA $(2 \mathrm{mM})$ and TTX $(0.5 \mu \mathrm{M})$ for at least $20 \mathrm{~min}$ 
A
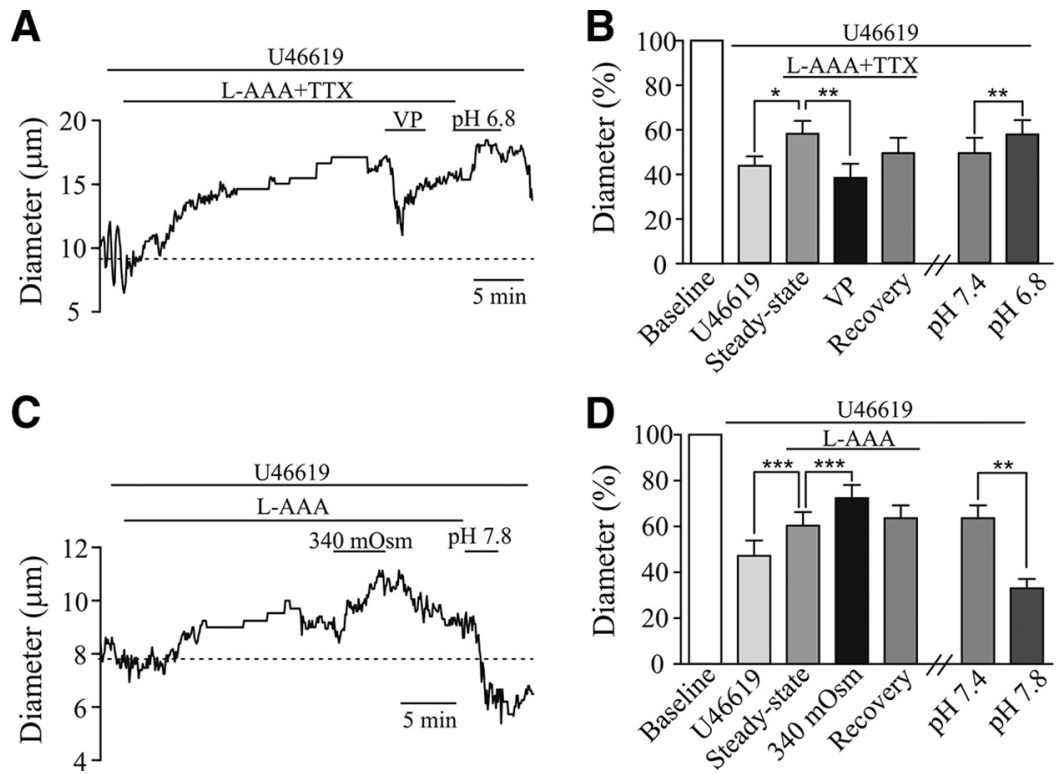

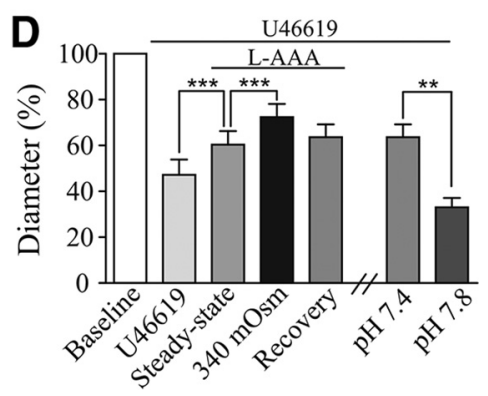

Figure 8. The effect of VP and hyperosmotic stimulation in the presence of compromised glia function. $\boldsymbol{A}$, Representative diameter trace showing VP-evoked vasoconstriction in the presence of the gliotoxin L-AAA, TTX, and U46619. B, Summary data of VP-evoked diameter (\%) changes in the presence of L-AAA, TTX, and U46619. C, Representative diameter trace during an osmotic stimulus in the presence of L-AAA and U46619. D, Summary data of osmotic stimulation-evoked diameter (\%) changes in the presence of L-AAA and U46619. Data are mean \pm SEM. Values were compared using tw0-way ANOVA followed by Bonferroni post-test. ${ }^{*} p<0.05{ }^{* *} p<0.01$. ${ }^{* * *} p<0.001$.

before exposing arterioles to bath-applied VP $(1 \mu \mathrm{M})$. TTX was added to prevent possible changes in neuronal activity subsequent to inhibition of astrocyte function. As shown in Figure $8 A$, $B$, the presence of TTX and L-AAA alone significantly reduced steady-state vascular tone by $\Delta 14 \pm 5 \%(n=7)$. Nonetheless, VP-induced vasoconstrictions $(\Delta-36 \pm 6 \%, n=7)$ persisted. Indicative of viable arterioles in this condition, acidosis, $\mathrm{pH} 6.8$, still induced a prominent vasodilation $(\Delta 21 \pm 6 \%, n=7$; Figure $8 A, B)$. As with TTX and L-AAA, the presence of L-AAA alone also significantly reduced vascular tone by $\Delta 13 \pm 3 \%$ (Figure $8 C, D$ ). Moreover, consistent with an astrocyte-independent mechanism, SON arterioles continued to dilate to hyperosmotic stimulation $(\Delta 22 \pm 4 \%, n=7)$. Together, these data suggest that, although astrocytes in the SON may contribute to the modulation of steadystate vascular tone, they are not key intermediaries in VP-mediated vasoconstriction of SON arterioles or the NVC response to hyperosmotic stimulation.

Given the complexity of the responses observed (i.e., variable magnitudes and onset times depending on the presence of pharmacological blockers during and after hyperosmotic stimulation), and for better comparison, we graphed peak vascular responses (\% change in diameter from baseline, $\Delta$ diameter $(\%)$ ) during the stimulus time and $4 \mathrm{~min}$ from the onset of the washout time (Fig. 9A). During the osmotic stimulation period, a clear vasodilatory response was observed $(\Delta 19 \pm 2 \%$, U46619), which was blunted in the presence of NOS blockade $(\Delta 9 \pm 2 \%$, L-NAME + cPTIO $)$ as well as the nNOS blocker 7-NI $(\Delta 11 \pm$ $5 \%)$. Consistent with the notion that vascular responses occur as a result of increased neuronal activity, diameter changes were significantly blocked by TTX $(\Delta 2 \pm 3 \%)$. Moreover, vasodilatory responses were significantly enhanced in the presence of V1a receptor blockade $(\Delta 35 \pm 8 \%$, U46619 + V2255) compared with the U46619 group alone. During the washout period, $\Delta$ diameter in the L-NAME + cPTIO group was significantly more constricted compared with the U46619 group ( $\Delta 5 \pm 3 \%$ vs $\Delta-10 \pm$
$4 \%)$. Interestingly, in the presence of 7-NI, the constriction observed during the washout period was absent, suggesting the potential contribution of NO from an eNOS source as well. In the presence of the V1a receptor blocker, dilations were significantly greater during the hyperosmotic stimulus and arterioles remained significantly more dilated during the washout period $(\Delta 23 \pm 8 \%$ vs $\Delta 5 \pm 3 \%$; Fig. $9 A$ ). Finally, the presence of the gliotoxin L-AAA did not alter the vascular response. In summary, these results support prominent NO-dependent vasodilatory responses to osmotically driven neuronal activity and a delayed VP-mediated vasoconstriction, which helps in the recovery of vascular tone as the absence of VP signaling prevented arterioles from recovery their diameter.

\section{Discussion}

In general, increased neuronal activity dilates cerebral arterioles. This process, known as NVC, ensures matching of neuronal metabolic demands with oxygen and nutrient supply. A component of the classical NVC model involves axonally released glutamate activation of metabotropic glutamate receptors in astrocytes and subsequent formation and release of vasodilatory signals (Attwell et al., 2010). However, whether this generalized NVC model is applicable to neuronal networks in which distinct and less conventional signaling transmitters are at play is unknown. To address this issue, we used the SON MNS as a working model, in which slowacting and far-diffusing neurotransmitters, including dendritically released neuropeptides and gaseous molecules, constitute key signals regulating neuronal/network activity (Ludwig and Leng, 2006). Here, not excluding the contribution of glutamate-mediated NVC, we unveiled a novel modality of NVC mediated by the competing action of opposing vasoactive signals whose balance and vascular effects are dependent on the stimulus conditions by which either a single or population of neurons are activated, namely, dendritically released VP and the gas molecule NO (Fig. 9B).

\section{Activity-dependent dendritic release of VP mediates local arteriole vasoconstriction}

The MNS along with nigral dopaminergic neurons stand as the best characterized systems for dendritic release of neurotransmitters in the CNS (Jaffe et al., 1998; Chen and Rice, 2001; Bergquist and Ludwig, 2008). Activity-dependent dendritic release of neuropeptides from MNNs is a calcium-dependent exocytotic event regulated independently from axonal release (Ludwig, 1998), constituting a polymodal functional role within the MNS. Acting as an autocrine population signal, it enables neurons to autoregulate their own firing activity, optimizing neurohypophysial hormone release during physiological challenges, including increases in plasma osmolarity or lactation (Ludwig and Leng, 1997; 2006). Moreover and as recently shown, slow-diffusing dendritically released VP acts as an interpopulation signal recruiting distant presympathetic neurons coordinating polymodal homeostatic responses to an osmotic challenge (Son et al., 2013). 
Supporting a vasoconstrictor role for dendritically released VP under near physiological vascular conditions, following single VP neuronal stimulation, using previously defined protocols to evoke dendritic release (Kombian et al., 1997; Son et al., 2013 Haam et al., 2014), a predominant V1a receptor-mediated vasoconstriction was observed in U46619preconstricted and pressurized/perfused arterioles with myogenic tone. A dendritic (rather than axonal) VP source is further supported by the topographical segregation between dendritic and axonal terminals characteristic of this system: axons from MNNs run dorsally and laterally, exiting the nucleus with scarce or no collaterals terminating within the SON or PVN (Swanson and Kuypers, 1980; Hatton et al., 1985). Dendrites, conversely, are confined within the nucleus, being mostly oriented ventrally (Armstrong, 1995). These characteristics minimized the possibility that axonal VP release contributed to activity-dependent vascular responses. Our studies suggest that, in addition to regulating local neuronal activity, dendritic VP release also contributes to concomitant adjustments in parenchymal arteriole tone. In agreement, a recent study reported osmotic stimulation-evoked vasoconstriction (in vivo) of extracerebral arterioles around the SON (Alonso et al., 2008).

Indicative of the release of a vasodilator and vasoconstrictor signal with different efficacies, in a few cases, we observed dilation followed by vasoconstriction in response to single VP neuronal stimulation. In support of this idea, blocking VPmediated vasoconstrictions unmasked an NO-mediated vasodilation. This is consistent with high nNOS expression in VP neurons (Arévalo et al., 1992) and their ability to release $\mathrm{NO}$ in an activitydependent manner (Pow, 1992; Kadowaki et al., 1994; Gillard et al., 2007). Thus, our results indicate that, although VP neuronal activation results in the corelease of opposing vasoactive signals, at the single VP-neuronal stimulation level, VP-mediated vasoconstriction generally prevailed. A similar competitive action between coreleased opposing vasoactive signals was reported in cortical NO-NPY-expressing GABAergic interneurons (Cauli et al., 2004). Finally, and contrary to our previous observations in the cortex (Blanco et al., 2008), the polarity of the vascular response (dilation vs constriction) to single VP neuronal stimulation was independent of the level of basal tone. Thus, vascular responses following activity-dependent dendritic release of VP stand as a novel and distinct form of NVC in the brain.

\section{Osmotically evoked NVC responses}

Activity-dependent vasoconstrictions following single VP neuronal stimulation were puzzling, given that increased neuronal activity is typically associated with increased CBF (Girouard and

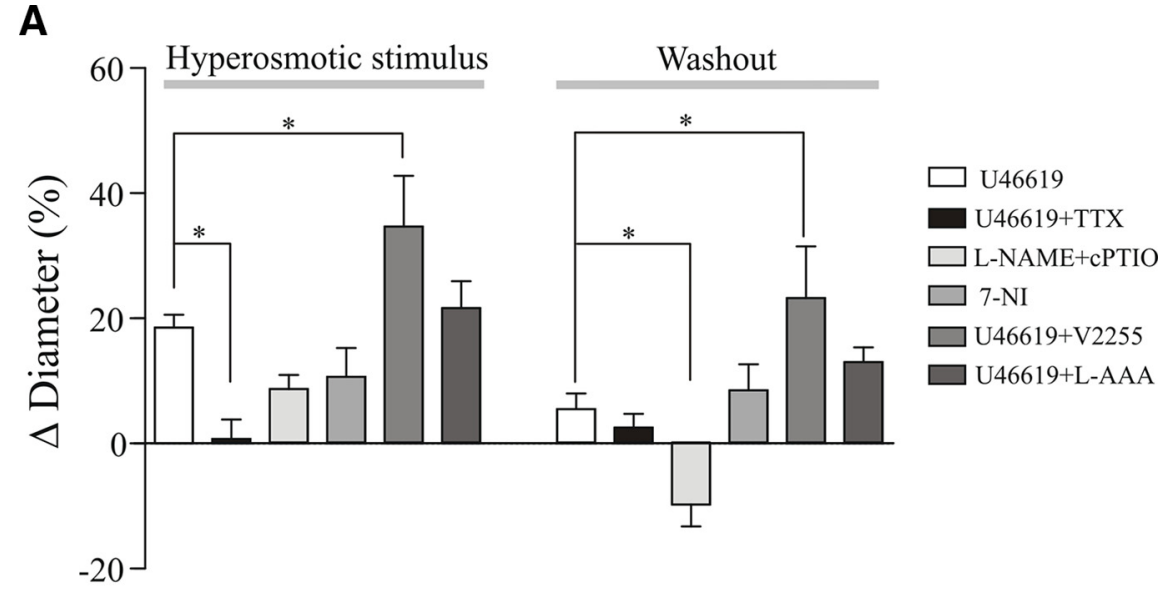

Figure 9. Comparison of vascular diameter changes among the different experimental conditions and working model for NVC mechanisms in the SON. $\boldsymbol{A}, 0$ smotically driven vascular diameter changes ( $\Delta$ diameter $\%$ ) in control conditions are compared with (V2255), or compromised glia function (L-AAA), during the stimulation period (far left), and 4 min after the onset of the washout period (far right). Data are mean \pm SEM. Values were compared using two-way ANOVA followed by Bonferroni post-test. ${ }^{*} p<$ 0.05. B, Working model illustrating possible NVC mechanisms at play in the SON.

Iadecola, 2006). It is important to consider, however, that to increase and maintain elevated systemic release of VP (Bourque, 1998 ) in response to physiological challenges (e.g., osmotic stimulus), the entire VP neuronal population is activated (Gouzènes et al., 1998). Additionally, to axonal systemic release of VP, osmotic stimulation also evokes local dendritic release of VP (Landgraf and Ludwig, 1991; Neumann et al., 1993), as well as NO (Gillard et al., 2007), with both signals acting in concert to efficiently regulate VP-mediated osmotic responses (Gillard et al., 2007). We found that, differently from single-neuronal stimulation, osmotically driven VP population activity resulted in a predominant and reversible vasodilation. Responses were abolished when action potentials were blocked with TTX, indicative of an activity-dependent neurovascular response. Our results also in- 
dicate that osmotically driven NVC in the SON is complex and, as in the cortex (Attwell et al., 2010), involves multiple signals.

Supporting NO as a key (but not only) vasodilatory signal, the magnitude of the osmotic stimulation-evoked vasodilation was partly blocked by L-NAME and the specific nNOS blocker 7-NI. Moreover, diminishing the magnitude of the vasodilation with L-NAME unmasked a delayed V1a receptor-dependent vasoconstriction; this vasoconstriction was absent in experiments conducted with 7-NI. These data support nNOS-derived NO as the immediate NVC signal and, likely, eNOS-derived NO as an additional/modulatory factor. The nature of additional vasodilatory signal(s) remains to be determined. Finally, in the presence of the V1a blocker, osmotic stimulation evoked a larger and sustained vasodilation, with no tone recovery. Thus, in the context of an osmotic stimulus, dendritic VP release may act to limit the magnitude of the evoked vasodilation while ensuring rapid baseline tone recovery. Along with previous studies showing that during an acute or chronic osmotic stimulation dendritic release of VP contributes to autoregulation of VP firing activity (Ludwig, 1998), recruitment of neighboring presympathetic neurons (Son et al., 2013), modulation of systemic release of VP (Gouzènes et al., 1998), and angiogenesis (Alonso et al., 2008), our studies support a pivotal role for activity-dependent dendritic VP release in orchestrating optimal vascular responses to an osmotic challenge.

Differences in the balance between activity-dependent VP and NO release may explain vascular responses observed between single (VP-mediated vasoconstriction) versus population (osmotic) (NOmediated vasodilation) neuronal stimulation. Alternatively, given that an osmotic stimulus also activates nNOS-expressing OT neurons (Neumann et al., 1993; Stern and Zhang, 2005) and eNOSexpressing cells (Stern and Zhang, 2005; Yuan et al., 2010), it is likely that enhanced NO release/availability originating from multiple sources, in addition to other vasodilatory signals, override VPmediated vasoconstriction. Of note, OT stimulation alone was not sufficient to evoke a vascular response. Importantly, consistencies were observed with the timing of the evoked vascular response with either single or osmotically driven stimulations; vasoconstrictions occurred with a delay following the stimulus and, when present, vasodilations preceded/overrode VP-mediated vasoconstrictions.

In the cortex and hippocampus, increased astrocytic $\mathrm{Ca}^{2+}$ mobilizes arachidonic acid metabolism, leading to the formation of vasoactive signals, which contribute to NVC (Attwell et al., 2010). VP has been shown to increase $\mathrm{Ca}^{2+}$ in astrocytes (Zhao and Brinton, 2003). However, in our study, the presence of the gliotoxin L-AAA, which leads to the intracellular depletion of glutathione (Kato et al., 1993; Pow, 2001) and inhibition of glialspecific enzymes (Chang et al., 1997), did not compromise VP-mediated vascular responses. L-AAA significantly reduced baseline vascular tone, yet VP evoked prominent vasoconstrictions. The notion that, in response to intense neuronal stimulation such as during lactation, dehydration, and parturition (Perlmutter et al., 1984, 1985; Chapman et al., 1986; Theodosis et al., 1986), glia processes retract, favors the participation of astrocytes in the modulation, rather than as key intermediaries, of the SON NVC response.

Our studies show that activity-dependent NVC in the MNS involves signals and mechanisms substantially different from those previously described (Attwell et al., 2010), highlighting dendritic release of peptides as a novel mechanism by which neurons locally influence vascular tone and CBF. Moreover, they further support multiple forms of NVC signaling modalities in the brain (Hamel, 2006), which appear to be determined in part by the variety of neurochemical signals released by activated neurons, as well as the particular stimulus mediating neuronal activation. Importantly, the observation that efficient SON NVC responses result from the balanced action of opposing activitydependent vasoactive signals (VP-NO) has important pathophysiological implications. In heart failure, for example, exacerbated neuronal activity in the SON/PVN contributes to neurohumoral activation (Patel et al., 2000; Zhang et al., 2002). Moreover, a profound decrease in nNOS and NO availability as well as increased VP levels have been reported in the SON/PVN during heart failure (Wang et al., 2005; Sivukhina et al., 2010; Sharma et al., 2011). Thus, imbalanced VP/NO levels during heart failure may compromise NVC responses, resulting in a mismatch in the neuronal metabolic demand-supply equilibrium. Future studies are needed to address the extent to which this imbalance contributes to alter SON neuronal activity and NVC in heart failure.

\section{References}

Alonso G, Gallibert E, Lafont C, Guillon G (2008) Intrahypothalamic angiogenesis induced by osmotic stimuli correlates with local hypoxia: a potential role of confined vasoconstriction induced by dendritic secretion of vasopressin. Endocrinology 149:4279-4288. CrossRef Medline

Apkon M, Boron WF (1995) Extracellular and intracellular alkalinization and the constriction of rat cerebral arterioles. J Physiol 484:743-753. CrossRef Medline

Arévalo R, Sánchez F, Alonso JR, Carretero J, Vázquez R, Aijón J (1992) NADPH-diaphorase activity in the hypothalamic magnocellular neurosecretory nuclei of the rat. Brain Res Bull 28:599-603. CrossRef Medline

Armstrong WE (1995) Morphological and electrophysiological classification of hypothalamic supraoptic neurons. Prog Neurobiol 47:291-339. CrossRef Medline

Attwell D, Buchan AM, Charpak S, Lauritzen M, Macvicar BA, Newman EA (2010) Glial and neuronal control of brain blood flow. Nature 468:232243. CrossRef Medline

Bergquist F, Ludwig M (2008) Dendritic transmitter release: a comparison of two model systems. J Neuroendocrinol 20:677-686. CrossRef Medline

Blanco VM, Stern JE, Filosa JA (2008) Tone-dependent vascular responses to astrocyte-derived signals. Am J Physiol Heart Circ Physiol 294:H2855H2863. CrossRef Medline

Bourque CW (1989) Ionic basis for the intrinsic activation of rat supraoptic neurones by hyperosmotic stimuli. J Physiol 417:263-277. CrossRef Medline

Bourque CW (1998) Osmoregulation of vasopressin neurons: a synergy of intrinsic and synaptic processes. Prog Brain Res 119:59-76. Medline

Brown CH, Bourque CW (2004) Autocrine feedback inhibition of plateau potentials terminates phasic bursts in magnocellular neurosecretory cells of the rat supraoptic nucleus. J Physiol 557:949-960. CrossRef Medline

Calka J, Block CH (1993) Relationship of vasopressin with NADPHdiaphorase in the hypothalamo-neurohypophysial system. Brain Res Bull 32:207-210. CrossRef Medline

Cauli B, Tong XK, Rancillac A, Serluca N, Lambolez B, Rossier J, Hamel E (2004) Cortical GABA interneurons in neurovascular coupling: relays for subcortical vasoactive pathways. J Neurosci 24:8940-8949. CrossRef Medline

Chang YF, Cauley RK, Chang JD, Rao VV (1997) L-Alpha-aminoadipate inhibits kynurenate synthesis in rat brain hippocampus and tissue culture. Neurochem Res 22:825-829. CrossRef Medline

Chapman DB, Theodosis DT, Montagnese C, Poulain DA, Morris JF (1986) Osmotic stimulation causes structural plasticity of neurone-glia relationships of the oxytocin but not vasopressin secreting neurones in the hypothalamic supraoptic nucleus. Neuroscience 17:679-686. CrossRef Medline

Chen BT, Rice ME (2001) Novel $\mathrm{Ca}^{2+}$ dependence and time course of somatodendritic dopamine release: substantia nigra versus striatum. J Neurosci 21:7841-7847. Medline

Chen YL, Shepherd C, Spinelli W, Lai FM (1999) Oxytocin and vasopressin constrict rat isolated uterine resistance arteries by activating vasopressin V1A receptors. Eur J Pharmacol 376:45-51. CrossRef Medline

Cipolla MJ, Smith J, Kohlmeyer MM, Godfrey JA (2009) SKCa and IKCa channels, myogenic tone, and vasodilator responses in middle cerebral 
arteries and parenchymal arterioles: effect of ischemia and reperfusion. Stroke 40:1451-1457. CrossRef Medline

da Silva MP, Ventura RR, Varanda WA (2013) Hypertonicity increases NO production to modulate the firing rate of magnocellular neurons of the supraoptic nucleus of rats. Neuroscience 250:70-79. CrossRef Medline

Dawson TM, Bredt DS, Fotuhi M, Hwang PM, Snyder SH (1991) Nitric oxide synthase and neuronal NADPH diaphorase are identical in brain and peripheral tissues. Proc Natl Acad Sci U S A 88:7797-7801. CrossRef Medline

Filosa JA, Bonev AD, Nelson MT (2004) Calcium dynamics in cortical astrocytes and arterioles during neurovascular coupling. Circ Res 95:e73-e81. CrossRef Medline

Filosa JA, Bonev AD, Straub SV, Meredith AL, Wilkerson MK, Aldrich RW, Nelson MT (2006) Local potassium signaling couples neuronal activity to vasodilation in the brain. Nat Neurosci 9:1397-1403. CrossRef Medline

Gillard ER, Coburn CG, de Leon A, Snissarenko EP, Bauce LG, Pittman QJ, Hou B, Currás-Collazo MC (2007) Vasopressin autoreceptors and nitric oxide-dependent glutamate release are required for somatodendritic vasopressin release from rat magnocellular neuroendocrine cells responding to osmotic stimuli. Endocrinology 148:479-489. CrossRef Medline

Girouard H, Iadecola C (2006) Neurovascular coupling in the normal brain and in hypertension, stroke, and Alzheimer disease. J Appl Physiol 100: 328-335. CrossRef Medline

Gouzènes L, Desarménien MG, Hussy N, Richard P, Moos FC (1998) Vasopressin regularizes the phasic firing pattern of rat hypothalamic magnocellular vasopressin neurons. J Neurosci 18:1879-1885. Medline

Haam J, Halmos KC, Di S, Tasker JG (2014) Nutritional state-dependent ghrelin activation of vasopressin neurons via retrograde trans-neuronalglial stimulation of excitatory GABA circuits. J Neurosci 34:6201-6213. CrossRef Medline

Hamel E (2006) Perivascular nerves and the regulation of cerebrovascular tone. J Appl Physiol 100:1059-1064. CrossRef Medline

Hatton GI, Cobbett P, Salm AK (1985) Extranuclear axon collaterals of paraventricular neurons in the rat hypothalamus: intracellular staining, immunocytochemistry and electrophysiology. Brain Res Bull 14:123-132. CrossRef Medline

Hatton GI, Bicknell RJ, Hoyland J, Bunting R, Mason WT (1992) Arginine vasopressin mobilises intracellular calcium via V1-receptor activation in astrocytes (pituicytes) cultured from adult rat neural lobes. Brain Res 588:75-83. CrossRef Medline

Huck S, Grass F, Hörtnagl H (1984) The glutamate analogue alphaaminoadipic acid is taken up by astrocytes before exerting its gliotoxic effect in vitro. J Neurosci 4:2650-2657. Medline

Iadecola C, Nedergaard M (2007) Glial regulation of the cerebral microvasculature. Nat Neurosci 10:1369-1376. CrossRef Medline

Jaffe EH, Marty A, Schulte A, Chow RH (1998) Extrasynaptic vesicular transmitter release from the somata of substantia nigra neurons in rat midbrain slices. J Neurosci 18:3548-3553. Medline

Kadowaki K, Kishimoto J, Leng G, Emson PC (1994) Up-regulation of nitric oxide synthase (NOS) gene expression together with NOS activity in the rat hypothalamo-hypophysial system after chronic salt loading: evidence of a neuromodulatory role of nitric oxide in arginine vasopressin and oxytocin secretion. Endocrinology 134:1011-1017. CrossRef Medline

Kato S, Ishita S, Sugawara K, Mawatari K (1993) Cystine/glutamate antiporter expression in retinal Muller glial cells: implications for DL-alphaaminoadipate toxicity. Neuroscience 57:473-482. CrossRef Medline

Kim KJ, Filosa JA (2012) Advanced in vitro approach to study neurovascular coupling mechanisms in the brain microcirculation. J Physiol 590: 1757-1770. CrossRef Medline

Kitaura H, Uozumi N, Tohmi M, Yamazaki M, Sakimura K, Kudoh M, Shimizu T, Shibuki K (2007) Roles of nitric oxide as a vasodilator in neurovascular coupling of mouse somatosensory cortex. Neurosci Res 59: 160-171. CrossRef Medline

Kombian SB, Mouginot D, Pittman QJ (1997) Dendritically released peptides act as retrograde modulators of afferent excitation in the supraoptic nucleus in vitro. Neuron 19:903-912. CrossRef Medline

Landgraf R, Ludwig M (1991) Vasopressin release within the supraoptic and paraventricular nuclei of the rat brain: osmotic stimulation via microdialysis. Brain Res 558:191-196. CrossRef Medline

Leng G (1980) Rat supraoptic neurones: the effects of locally applied hypertonic saline. J Physiol 304:405-414. CrossRef Medline
Loichot C, Krieger JP, De Jong W, Nisato D, Imbs JL, Barthelmebs M (2001) High concentrations of oxytocin cause vasoconstriction by activating vasopressin V1A receptors in the isolated perfused rat kidney. Naunyn Schmiedebergs Arch Pharmacol 363:369-375. CrossRef Medline

Lourenço CF, Santos RM, Barbosa RM, Cadenas E, Radi R, Laranjinha J (2014) Neurovascular coupling in hippocampus is mediated via diffusion by neuronal-derived nitric oxide. Free Radic Biol Med 73:421-429. CrossRef Medline

Lovick TA, Brown LA, Key BJ (1999) Neurovascular relationships in hippocampal slices: physiological and anatomical studies of mechanisms underlying flow-metabolism coupling in intraparenchymal microvessels. Neuroscience 92:47-60. CrossRef Medline

Ludwig M (1998) Dendritic release of vasopressin and oxytocin. J Neuroendocrinol 10:881-895. CrossRef Medline

Ludwig M, Leng G (1997) Autoinhibition of supraoptic nucleus vasopressin neurons in vivo: a combined retrodialysis/electrophysiological study in rats. Eur J Neurosci 9:2532-2540. CrossRef Medline

Ludwig M, Leng G (2006) Dendritic peptide release and peptide-dependent behaviours. Nat Rev Neurosci 7:126-136. CrossRef Medline

MacGregor DJ, Leng G (2013) Spike triggered hormone secretion in vasopressin cells: a model investigation of mechanism and heterogeneous population function. PLoS Comput Biol 9:e1003187. CrossRef Medline

Maigaard S, Forman A, Andersson KE (1986) Differential effects of angiotensin, vasopressin and oxytocin on various smooth muscle tissues within the human uteroplacental unit. Acta Physiol Scand 128:23-31. CrossRef Medline

Metea MR, Newman EA (2006) Glial cells dilate and constrict blood vessels: a mechanism of neurovascular coupling. J Neurosci 26:2862-2870. CrossRef Medline

Mulligan SJ, MacVicar BA (2004) Calcium transients in astrocyte endfeet cause cerebrovascular constrictions. Nature 431:195-199. CrossRef Medline

Neumann I, Ludwig M, Engelmann M, Pittman QJ, Landgraf R (1993) Simultaneous microdialysis in blood and brain: oxytocin and vasopressin release in response to central and peripheral osmotic stimulation and suckling in the rat. Neuroendocrinology 58:637-645. CrossRef Medline

Nylén A, Skagerberg G, Alm P, Larsson B, Holmqvist BI, Andersson KE (2001) Detailed organization of nitric oxide synthase, vasopressin and oxytocin immunoreactive cell bodies in the supraoptic nucleus of the female rat. Anat Embryol (Berl) 203:309-321. CrossRef Medline

Oyama H, Suzuki Y, Satoh S, Kajita Y, Takayasu M, Shibuya M, Sugita K (1993) Role of nitric oxide in the cerebral vasodilatory responses to vasopressin and oxytocin in dogs. J Cereb Blood Flow Metab 13:285-290. CrossRef Medline

Patel KP, Zhang K, Kenney MJ, Weiss M, Mayhan WG (2000) Neuronal expression of Fos protein in the hypothalamus of rats with heart failure. Brain Res 865:27-34. CrossRef Medline

Perlmutter LS, Tweedle CD, Hatton GI (1984) Neuronal/glial plasticity in the supraoptic dendritic zone: dendritic bundling and double synapse formation at parturition. Neuroscience 13:769-779. CrossRef Medline

Perlmutter LS, Tweedle CD, Hatton GI (1985) Neuronal/glial plasticity in the supraoptic dendritic zone in response to acute and chronic dehydration. Brain Res 361:225-232. CrossRef Medline

Pow DV (1992) NADPH-diaphorase (nitric oxide synthase) staining in the rat supraoptic nucleus is activity-dependent: possible functional implications. J Neuroendocrinol 4:377-380. CrossRef Medline

Pow DV (2001) Visualising the activity of the cystine-glutamate antiporter in glial cells using antibodies to aminoadipic acid, a selectively transported substrate. Glia 34:27-38. CrossRef Medline

Rancillac A, Rossier J, Guille M, Tong XK, Geoffroy H, Amatore C, Arbault S, Hamel E, Cauli B (2006) Glutamatergic control of microvascular tone by distinct GABA neurons in the cerebellum. J Neurosci 26:6997-7006. CrossRef Medline

Sharma NM, Zheng H, Mehta PP, Li YF, Patel KP (2011) Decreased nNOS in the PVN leads to increased sympathoexcitation in chronic heart failure: role for CAPON and Ang II. Cardiovasc Res 92:348-357. CrossRef Medline

Shen Z, Lu Z, Chhatbar PY, O’Herron P, Kara P (2012) An artery-specific fluorescent dye for studying neurovascular coupling. Nat Methods 9:273276. CrossRef Medline

Sivukhina EV, Morozov IuE, Dolzhikov AA, Jirikowski GF, Grinevich V (2010) Comparison of vasopressin and oxytocin expressions in the 
hypothalamo-neurohypophysial system of patients with chronic heart failure. Horm Metab Res 42:56-60. CrossRef Medline

Son SJ, Filosa JA, Potapenko ES, Biancardi VC, Zheng H, Patel KP, Tobin VA, Ludwig M, Stern JE (2013) Dendritic peptide release mediates interpopulation crosstalk between neurosecretory and preautonomic networks. Neuron 78:1036-1049. CrossRef Medline

Stern JE, Zhang W (2005) Cellular sources, targets and actions of constitutive nitric oxide in the magnocellular neurosecretory system of the rat. J Physiol 562:725-744. CrossRef Medline

Suzuki Y, Satoh S, Kimura M, Oyama H, Asano T, Shibuya M, Sugita K (1992) Effects of vasopressin and oxytocin on canine cerebral circulation in vivo. J Neurosurg 77:424-431. CrossRef Medline

Swanson LW, Kuypers HG (1980) The paraventricular nucleus of the hypothalamus: cytoarchitectonic subdivisions and organization of projections to the pituitary, dorsal vagal complex, and spinal cord as demonstrated by retrograde fluorescence double-labeling methods. J Comp Neurol 194: 555-570. CrossRef Medline

Takano T, Tian GF, Peng W, Lou N, Libionka W, Han X, Nedergaard M (2006) Astrocyte-mediated control of cerebral blood flow. Nat Neurosci 9:260-267. CrossRef Medline

Theodosis DT, Montagnese C, Rodriguez F, Vincent JD, Poulain DA (1986) Oxytocin induces morphological plasticity in the adult hypothalamoneurohypophysial system. Nature 322:738-740. CrossRef Medline

Ueta Y, Fujihara H, Serino R, Dayanithi G, Ozawa H, Matsuda K, Kawata M,
Yamada J, Ueno S, Fukuda A, Murphy D (2005) Transgenic expression of enhanced green fluorescent protein enables direct visualization for physiological studies of vasopressin neurons and isolated nerve terminals of the rat. Endocrinology 146:406-413. CrossRef Medline

Wang Y, Liu XF, Cornish KG, Zucker IH, Patel KP (2005) Effects of nNOS antisense in the paraventricular nucleus on blood pressure and heart rate in rats with heart failure. Am J Physiol Heart Circ Physiol 288:H205H213. CrossRef Medline

Yuan H, Gao B, Duan L, Jiang S, Cao R, Xiong YF, Rao ZR (2010) Acute hyperosmotic stimulus-induced Fos expression in neurons depends on activation of astrocytes in the supraoptic nucleus of rats. J Neurosci Res 88:1364-1373. CrossRef Medline

Zhang ZH, Francis J, Weiss RM, Felder RB (2002) The renin-angiotensinaldosterone system excites hypothalamic paraventricular nucleus neurons in heart failure. Am J Physiol Heart Circ Physiol 283:H423-H433. CrossRef Medline

Zhao L, Brinton RD (2003) Vasopressin-induced cytoplasmic and nuclear calcium signaling in embryonic cortical astrocytes: dynamics of calcium and calcium-dependent kinase translocation. J Neurosci 23:4228-4239. Medline

Zonta M, Angulo MC, Gobbo S, Rosengarten B, Hossmann KA, Pozzan T, Carmignoto G (2003) Neuron-to-astrocyte signaling is central to the dynamic control of brain microcirculation. Nat Neurosci 6:43-50. CrossRef Medline 